Tesis. Año 12, 11(13), 2018, 77-91

\title{
Balance de la vanguardia literaria en Trilce
}

\author{
Olga Judith Tello C. \\ olgatellocuskisiban@yahoo.es
}

\section{Resumen}

Analiza Trilce (1922), el segundo libro de poemas de César Vallejo que revolucionó los espacios de la crítica literaria peruana e hispanoamericana y generó desconcierto ante la trasformación radical del lenguaje poético. Representa la ruptura con la estética tradicional, con la insuficiencia del discurso poético establecido. La investigación plantea que es una creación particular, no obstante, contiene elementos que coinciden con la vanguardia literaria de la época y que la escritura poética traspasa y crea el arte nuevo.

Palabras clave: César Vallejo, vanguardia literaria, Trilce, escritura poética.

\begin{abstract}
Analyzes Trilce (1922), the second book of poems by César Vallejo that revolutionized the spaces of Peruvian and Latin American literary criticism and generated confusion over the radical transformation of poetic language. Representative of the break with traditional aesthetics, with the insufficiency of established poetic discourse. The research suggests that it is a particular creation, however, it contains elements that coincide with the literary avant-garde of the time and poetic writing transcends and creates new art.
\end{abstract}

Keywords: César Vallejo, literary avant-garde, Trilce, writing poetry. 


\section{Balance de la vanguardia literaria en Trilce}

\section{La vanguardia literaria}

La vanguardia es el nombre colectivo que reciben las diversas tendencias artísticas (los llamados ismos) que surgen en Europa durante las primeras décadas del siglo XX, así lo refiere Verani (1995). Este movimiento propone "el rechazo a la figuratividad y la representación, el fundamento constructivo de la nueva forma, su condición abstracta y la relevancia espacial de su concepción y percepción [...]" (Bürger 2000, p. 12). Es decir, el rechazo de la idea de arte como mimesis de la realidad. La obra de arte vanguardista renuncia a la función de traducir o crear un contexto específico ajena a su propio universo; el propósito es representar la realidad tal como es y no lo que aparenta. Así expresa su modo particular de referirse a lo existente.

La vanguardia literaria surge en Hispanoamérica como consecuencia de la influencia de los "ismos" europeos y de un profundo cuestionamiento a la tradición, el culto a la belleza y a la armonía estética; se propone una búsqueda de las nuevas formas literarias, las cuales quebrantan el lenguaje racional para expresar visualmente la ruptura con la simetría clásica (Verani 1995, p. 10). Estos cambios se manifiestan en diversos panoramas culturales y, además, corresponden al periodo de transformaciones ideológicas y políticas de inicios del siglo XX como la Primera Guerra Mundial entre los años 1914 y 1918; la Revolución Soviética o Revolución bolchevique en 1917. Luego el gran desastre de la bolsa de Wall Street en 1929 que volvería a producir una recesión y conflictos llevando a la aparición de regímenes totalitarios (fascismo y nazismo) que conducirán a la Segunda Guerra Mundial.

Así los contextos culturales de la época refieren que:

Es aquella época de grandes y vitales inquietudes, en las que conviven tendencias de todo tipo, con caracteres muy dispersos, que comparten la urgencia de descubrir nuevas posibilidades expresivas y el rechazo de 
la estética simbolista decadente, desajustada con la circunstancia social que se vivía. Junto a los ismos que testimonian una estéril negación total del pasado (el futurismo italiano, 1909; el dadaísmo de Tristán Tzara, 1916), otras tendencias más influyentes y perdurables (el expresionismo alemán, 1911; el imaginismo inglés de Ezra Pound, 1912; el cubismo literario de Guillaume Apollinaire, 1914) siguen caminos desconocidos que avizora el surrealismo (1924), que viene a ser la cristalización de los objetivos de la vanguardia internacional. (Verani 1995, pp. 9-10)

En cuanto a los espacios temporales de la vanguardia hispanoamericana existen distintas opiniones (Schwartz 2002, Schopf 1986, Osorio 1982). No obstante, hemos tenido en cuenta las fechas límites propuesta por Verani, 1916 y 1935, considerando su apogeo entre 1920 y 1930. Asimismo, existe otra fecha que es clave, y a la que se le atribuye el inicio de los movimientos vanguardista en nuestra región: 1922, ese año "se celebra la Semana del Arte Moderno en Sao Paulo, se funda Proa en Buenos Aires, se publica Trilce de César Vallejo, Veinte poemas para ser leidos en el tranvia de Oliverio Girondo, Andamios interiores de Manuel Maples Arce y Desolación de Gabriela Mistral, [...]" (Verani 1995, p. 11). Cabe señalar que la publicación de Trilce se realiza ese mismo año, quizás sea la razón que ha llevado a buena parte de la crítica a denominar a este libro como vanguardista.

En la literatura universal, 1922 constituye también una fecha importante para la renovación estética, pues se publican Ulises de James Joyce, Tierra baldía de T. S. Eliot, Babbit de Sinclair Lewis, El cuarto de Jacob de Virginia Wolf, Fantasía de D. H. Lawrence, Charmes de Paul Valery, Duración y simultaneidad de Henry Bergson, Siddharta de Herman Hesse, Baal de Bertold Brecht, Sonetos de Orfeo de Rainer María Rilke, La decadencia de Occidente de Oswaldo Spengler, Enrico IV de Luigui Pirandelo.

De otro lado en el Perú, la vanguardia se produjo en un momento de cambios y conmociones sociales: surgió un movimiento político, populista, encabezado por Guillermo Billinghurst, quien triunfa en las elecciones de 1912. A pesar de tratarse de un gobierno de apenas dos años, se trataba, de autoridades elegidas por primera vez por las masas populares; a este hecho hay que sumar la huelga general de 1919. Ambas fechas marcan, según Delgado (1980), una nueva etapa en la historia del Perú.

Las primeras manifestaciones del movimiento vanguardista se establecen alrededor de los años de 1915 o 1916 y se prolonga hasta 1940, incluso se extiende algunos años más, como lo refiere Delgado (1980). La plenitud del vanguardismo peruano se sitúa entre 1920 y 1930. En esta década se nota el predominio de la poesía sobre los demás géneros literarios. En relación con el panorama cultural de la época, Luis Alberto Sánchez refiere que las actividades 
intelectuales como la Reforma Universitaria, la fundación del Partido Aprista, la aparición en el Perú del socialismo y el comunismo, el libro Siete ensayos de interpretación de la realidad peruana (1928) de Mariátegui, los Cuentos Andinos de López Albújar, entre otros, no tuvieron relación con la vanguardia.

Siguiendo a Delgado (1980), referimos que el movimiento vanguardista en el Perú al igual que en los otros países latinoamericanos se interesó por las novedades del siglo XX: la máquina, el deporte, la velocidad. Nuestra vanguardia no mantuvo la pureza estética de los "ismos" europeos. No se desarrollaron de una manera diferenciada e independiente movimientos cubistas, creacionistas, ultraístas, surrealistas o expresionistas, se puede señalar que en general nuestros vanguardistas poseían una vitalidad expresiva y un tono emocional que se aleja de la fría objetividad impersonal de los "ismos" europeos más extremados, como lo podemos notar con la obra poética de César Vallejo, Carlos Oquendo o Martí Adán y aún en los surrealistas más refinados como Westphalem y César Moro.

\section{Trilce y la vanguardia}

La vanguardia en el Perú se inicia temprano, Alberto Hidalgo es el representante de este proceso, un poeta que realiza una intensa actividad literaria y cuya poesía Panopla lírica (1917) constituye una rebelión de carácter futurista. Es así como en su poema "La nueva poesía: Manifiesto", promueve el dinamismo de la nueva civilización: el maquinismo; la velocidad, la virilidad. Emplea la característica de la poesía de vanguardia: la pérdida de sentido de continuidad, los elementos discordantes e incoherentes en la estructura del poema.

Dentro del periodo vanguardista peruano, se ha señalado a dos libros de gran valor literario, Trilce (1922) y los Siete ensayos de la interpretación de la realidad peruana (1928), libros fundamentales para el Perú y Latinoamérica; sin dejar de mencionar otros y la abundante poesía que se publicó en revistas de la época. Entre las que destacan: "Flechas" (1924), luego en 1926 aparecen otras de corta duración «y revelan el vigor vanguardista de la época "Hangar-Rascacielos-Timonel-Trampolín” (1926-1927), revista que fue cambiando de nombre en cada uno de sus cuatro números, "Poliedro" (1926), "Hurra" (1927), "Guerrilla” (1927), etcétera.>> (Verani 1995, p. 29). No podemos dejar de mencionar a la revista más importante que irradio la cultura en el Perú, "Amauta" (19261930), fundada por José Carlos Mariátegui quien escribió artículos y ensayos.

Conviene distinguir que, el movimiento vanguardista peruano tan igual que en los países de Latinoamérica impulsó la renovación estética, rindió culto a la poesía, pero, reivindicó los valores autóctonos, no fue una copia servil. Buscó una identidad nacional, y a la vez una expresión universal y personal. En el Perú, "[...] la defensa del pasado y el presente indígena y por el propósito de 
incorporar elementos de la tradición cultural andina en el arte y la literatura". (Manuel Burga y Alberto Flores 1980, p. 17)

Es significativa la importancia que, tiene la poesía de Trilce, Vallejo es un renovador absoluto, pero, no se identifica totalmente con las modas de uso. La diferencia con el vanguardismo que buscaba una poesía objetiva a base de la frivolidad lúdica e intelectual, las imágenes insólitas, el poeta se mira a sí mismo y su poesía es la expresión cabal de sus emociones. Y en este afán desesperado de dar cuenta de sus sentimientos adecúa el sentir a la forma. Esa forma oscura, hermética del vocabulario descubre la vida espiritual, la nostalgia por el hogar, el recuerdo de la madre, la infancia perdida, el amor, los días de prisión constituyen el fundamento del poemario, y de su poética singular.

\section{Trilce}

Las composiciones trílcicas, tituladas con números romanos de I a LXXVII no llevan título, no siguen ningún orden cronológico ni temático. En cuanto al nombre de Trilce existen variadas explicaciones de cómo surge la palabra. Sin embargo, hemos tomado la versión de su amigo y biógrafo, Espejo Asturrizaga.

[...] Por varios días repitió tres, tres, tres, con esa insistencia que tenía en repetir palabras y deformarlas, tressss, trissss, trieesss, tril, trilssss. Se le trabó la lengua y en el ceceo salió trilsssce... ¿trilce? ¿trilce? Se quedó unos instantes en suspenso para luego exclamar: "Bueno, llevaría mi nombre pero el libro se llamará Trilce". [...] Posteriormente se han dado diversas versiones sobre esta palabra. César ha contribuido, en muchas ocasiones, a sembrar confusión en relación con su origen. Así a un $X$, que alguna vez le preguntó el por qué le había puesto a su extraño libro el nombre de Trilce César respondió: "Pues porque vale tres soles" usando ese humorismo que sabía emplear [...]. (p. 136)

\section{Trilce y los movimientos de vanguardia}

Las posibles influencias de los movimientos vanguardistas de Trilce refieren que el poeta pudo conocer la revista "Cervantes". Al respecto, "Alcides Spelucín ha precisado que los compañeros de generación comenzaron a leer "Cervantes" en 1917, y la continuaron leyendo después que surgió el movimiento ultraísta en España; [...]" (Martos y Villanueva 1989, p. 18). Otra de las revistas que se menciona que leyó Vallejo es "Grecia" cuya temática está alejada de los ideales vanguardistas. En cambio, no existen referencias que señalen que conociera las revistas ultraístas "Ultra" (1919) y "Tableros" (1921), simultáneas a la publicación de Trilce. Todo ello, va mostrando que el poemario constituye una creación particular alejada de la influencia de las escuelas vanguardistas. 
En relación con las posibles o reales lecturas de la vanguardia literaria, los críticos Martos y Villanueva refieren que el poemario presenta coincidencias a la vez que diferencias con la vanguardia. Y señalan los aspectos en común: el uso de los números, de las mayúsculas, la supresión ocasional de nexos lógicos, la distribución arbitraria de los versos y el uso de la onomatopeya. Como caracteres contrarios de la vanguardia que se expone en Trilce, tenemos: el tema autobiográfico, la anécdota y, de otro lado, rezagos métricos en algunos poemas de clara raigambre modernista que fueron originalmente sonetos.

Asimismo se ha señalado que:

Trilce es un libro surrealista. Nada más alejado de la realidad. Por supuesto que el surrealismo no existía como movimiento en 1922, pero al mismo tiempo Vallejo no pudo ser un surrealista "avant la lettre" porque se proponía hacer lo contrario de los surrealistas. En un poema surrealista una imagen puede reemplazar a otra con la que tenga parecido nivel de ensoñación; en Trilce el vocablo es importante en si mismo, irreemplazable, ceñido, austero. (Martos y Villanueva 1989, p. 20, énfasis mío)

Cabe destacar que, Vallejo señaló en "Autopsia del superrealismo" que: “[...] el surrealismo, como escuela literaria, no representaba ningún aporte constructivo. Era una receta más de hacer poemas sobre medida, como lo son y serán las escuelas literarias de todos los tiempos" (ctd en Puccinelli, p. 399). El poeta no solo muestra su rechazo al surrealismo sino que criticó, en su artículo "Contra el secreto profesional", fuertemente a los poetas latinoamericanos que siguieron las formas artísticas del vanguardismo. Otro argumento más para referir que el poemario no corresponde a una creación vanguardista.

En cuanto a las notas contrarias al movimiento vanguardista, Vallejo presenta desde el hermetismo de su escritura y el aparente discurso ilógico de las composiciones trílcicas un proceso de redescubrimiento del lenguaje. Por consiguiente, hemos seleccionado tres composiciones: I, LXXVII, XXXVI, para exponer la nueva poética y demostrar que la impronta vanguardista no corresponde al poemario.

Ahora bien, iniciemos el análisis de Tr. I denominado el poema del parir metafórico. El discurso poético refiere el alumbramiento de la escritura poética. En esta composición, Vallejo enuncia la nueva poética. Leamos el poema en su integridad:

Quién hace tánta bulla y ni deja

testar las islas que van quedando. 
Un poco más de consideración

en cuanto será tarde, temprano,

y se aquilatará mejor

el guano, la simple calabrina tesórea

que brinda sin querer,

en el insular corazón

salobre alcatraz, a cada hialóidea

grupada.

Un poco más de consideración, y el mantillo líquido, seis de la tarde

DE LOS MÁS SOBERBIOS BEMOLES.

Y la península párase

por la espalda, abozaleada, impertérrita

en la línea mortal del equilibrio.

En cuanto a la escritura, observamos el uso del neologismo, "tesórea 'tesoro + ea" Meo de Zilio (ctd en Martos y Villanueva, p. 44); los que se crean a partir de palabras existentes. Vallejo parte de una realidad lingüística que él experimenta. Esta es la diferencia con el vanguardismo que presta términos lingüísticos ("cinema, motor, caballos de fuerza, avión, radio, jazz-band, telegrafía sin hilos, en general, todas las voces de las ciencias e industrias contemporáneas [...]" Vallejo (ctd Verani p. 190). De ahí que, Trilce se constituye como una obra de creación singular.

Utiliza también el peruanismo, guano (voz quechua); y los coloquialismos, abozaleada y bulla; vocablos que reproducen el sentido que el poeta le otorga al mundo. Vinculamos la idea de ruido con el contexto hostil en que se crea el poema. Este ambiente refiere el espacio carcelario y; surge la idea de ruido. A la que hemos vinculado con las renovaciones de los "ismos" europeos. Vallejo cuestiona este movimiento vanguardista que irrumpe en corto tiempo con nuevas y diversas escuelas literarias que dificultan el auténtico quehacer literario.

Lo primero que destaca en esta estrofa es una interrogación que, a pesar de haberse ignorado los signos de interrogación, es claramente una pregunta retórica (cf. Martos y Villanueva, p. 46); es decir, está hecha sin el fin de obtener una respuesta; sin embargo, esta pregunta se puede tomar como un reclamo o queja.

Quién hace tánta bulla, y ni deja (v.1)

Asimismo, reflexiona como creador frente a su yo poético. Se contempla a sí mismo como sujeto creador. Y explica a través de la metáfora de la defecación la evolución de la nueva escritura poética. 
y se aquilatará mejor (v.5)

el guano, la simple calabrina tesórea

que brinda sin querer,

en el insular corazón,

salobre alcatraz, a cada bialóidea

grupada

y el mantillo líquido, seis de la tarde (v.12)

DE LOS MÁS SOBERBIOS BEMOLES

Y la peninsula párase

por la espalda, abozaleada, impertérrita

(Énfasis mío)

Por supuesto, no solo describe el acto fisiológico de la defecación, sino que a partir de esa metáfora que constituye un proceso de significación; observamos que la expulsión de las heces hace la mimesis de parto. Este parir metafórico en el discurso de la composición I representa el alumbramiento de la nueva escritura. Cabe añadir que, a partir de ciertas interpretaciones se puede sostener que la metáfora de la defecación alude el quehacer literario. Sumando a esto, desde la mirada de la antropología, así como del psicoanálisis, se plantea una relación entre lo escatológico y la creación literaria.

El poema I es revelador: señala la ruptura con la temática modernista y poetiza un tema extremadamente humano, el acto de la defecación que la retórica clásica no observa como elemento de belleza lírica. Así, Vallejo a partir de esta metáfora va enunciando su escritura poética. La que ha transformado radicalmente el lenguaje sometiéndolo a una reelaboración lexical. Aquí las palabras poseen "un doble significado objetivo y subjetivo, universal y singular, conceptual y emocional. Es siempre el segundo el que interesa sobre todo al poeta". (Ferrari 1998, p. 250)

Habría que decir también que, Vallejo no solo deja traslucir su incertidumbre como artista que enfrenta un medio hostil, sino que se contempla a sí mismo como un sujeto creador - poema I-, y como objeto de la creación artística, particularmente en el poema que presentamos a continuación:

\section{LXXVII}

Graniza tanto, como para que yo recuerde 1

y acrecienta las perlas

que he recogido del hocico mismo

de cada tempestad.

No se vaya a secar esta lluvia.

A menos que me fuese dado 
caer ahora para ella, o que me enterrasen

mojado en el agua

que surtiera de todos los fuegos

¿Hasta dónde me alcanzará esta lluvia?

Temo me quede con algún flanco seco; temo que ella se vaya, sin haberme probado en las sequías de increíbles cuerdas vocales, por las que para dar armonía,

hay siempre que subir nunca que bajar!

¿No subimos acaso para abajo?

¡Canta, lluvia, en la costa aún sin mar!

Siguiendo a Neale Silva (1975), tenemos el esquema de la representación del poema:

\begin{tabular}{|c|c|c|c|c|c|}
\hline $\begin{array}{c}\text { I } \\
\text { todos los } \\
\text { fuegos }\end{array}$ & $\begin{array}{c}\text { II } \\
\text { creador } \\
\text { (sujeto) }\end{array}$ & $\begin{array}{c}\text { III } \\
\text { "graniza } \\
\text { (b) } \\
\text { tempestad } \\
\text { (objeto) }\end{array}$ & $\begin{array}{c}\text { agua } \\
\text { (lluvia } \\
\text { (inspiración) }\end{array}$ & $\begin{array}{c}\text { armonía } \\
\text { (creación } \\
\text { lírica) }\end{array}$ & $\begin{array}{c}\text { perlas } \\
\text { (poema) }\end{array}$ \\
\hline
\end{tabular}

Las relaciones propuestas por el crítico son acertadas, en cuanto refiere la correlación entre el creador, el yo; y un ente objetivo, esto es, la tempestad. E1 proceso del acto creador se presenta a partir de la iluminación representada por graniza; y la inspiración, en el agua y la lluvia. Todo ello se materializa en el poema representado en las perlas. Lo que se traduce en la creación lírica o la armonía que refiere el poeta. La disposición de estos elementos es posible a través del genio poético simbolizado en el fuego.

Observamos que en Tr. I y Tr. LXXVII no refieren una teoría poética, no existe reglas, no es un arte poético solo se da cuenta de la vivencia del poeta que se contempla a sí mismo en la función de escribir. Así lo establece también Neale Silva quien sostiene que estos poemas:

presentan dos trances dramáticos en la vida del creador literario, y no un "Manifiesto", del tipo que fue tan común entre los poetas vanguardistas. En ellos hay "oscuridades" de léxico o de intención, pero no de significado. Entre las oscuridades de intención hay que poner la arquitectura de los poemas y su contenido simbólico. Tr. I y Tr. LXXVII como hemos visto tienen una organización coherente, pero su unidad 
no descansa en el uso de recursos obvios, sino en interrelaciones, a veces muy sutiles, entre contenidos espirituales (Id. p. 49).

Vallejo, a diferencia de muchos poetas, no señala su dolor y su protesta; él registra cabalmente su universo espiritual y, para ello, elabora un lenguaje particular que constituye la ruptura con el mundo tradicional e idealista. La escritura refiere la tensión del poeta ante la dificultad de las palabras para decir su pensamiento. De ahí que el léxico complejo de su poesía este en función de su visión del mundo.

Conviene distinguir que el año de 1922 constituye una época clave en el desarrollo del movimiento vanguardista en Europa y América Latina. En este sentido, la publicación de Trilce (1922), traspasó todos estos acontecimientos, pues el poemario constituye una creación estética impar. Por ello, no se puede pensar que Vallejo recibió la influencia de los "ismos" europeos. Aunque, la obra denote la utilización de postulados, los que establecen coincidencias, mas no una imitación. La posición de Vallejo frente a la vanguardia literaria fue siempre contraria. La criticó en su "Autopsia del superrealismo" y decía que jamás el pensamiento social se fraccionó en tantas y tan fugaces fórmulas. Refutó además la necesidad de estereotiparse en recetas y clisé. Al respecto se refiere que "Vallejo rechaza la poesía como producto de una técnica o preceptiva y se mantiene al margen de toda escuela o movimiento. [...] Lo que cambia, en Trilce, es el tratamiento de su escritura para trasmitir su percepción del mundo" (Verani 1995, p. 28).

De todo lo anterior, podemos señalar que la escritura trílcica busca expresar lo inefable, lo que quiere decir aquello que las palabras no pueden decir, esto determinará la reelaboración del lenguaje. La palabra se adecua al sentido que el poeta le otorga al mundo. Comprendamos que "la imperfección de la palabra [...] corresponde a la angustia ante la imperfección de la existencia." (Ferrari 1999, p. 198) En consecuencia, la poesía trílcica anota una continua desarmonía que se configura de búsquedas y rechazos, de límites e imperfecciones.

En el orden de las ideas anteriores el vate santiaguino ha de revelar su poesía en función del modo de entender la realidad. Considera la escritura como un elemento esencial de un mundo, y la poética establecida presenta una inadecuación profunda entre la palabra y el universo afectivo que debe expresar. Leamos ahora la composición en su totalidad:

\section{XXXVI}

Pugnamos ensartarnos por el ojo de una aguja, enfrentados a las ganadas.

Amoniácase casi el cuarto ángulo del círculo. 
¡Hembra se continúa al macho, a raíz

de probables senos, y precisamente

5

a raíz de cuanto no florece!

¿Por ahí estás, Venus de Milo?

Tu manqueas apenas pululando

entrañada en los brazos plenarios

de la existencia,

de esta existencia que todaviiza

perenne imperfección.

Venus de Milo, cuyo cercenado, increado

brazo revuélvese y trata de encodarse

a través de verdeantes guijarros gagos,

ortivos nautilos, aunes que gatean

recién, vísperas inmortales.

Laceadora de inminencias, laceadora

del paréntesis.

Rehusad, y vosotros, a posar las plantas

en la seguridad dupla de la Armonía.

Rehusad la simetría a buen seguro.

Intervenid en el conflicto

de puntas que se disputan

en la más torionda de las justas

el salto por el ojo de la aguja.

La composición reitera la idea de desarmonía simbolizada en Venus de Milo (escultura considerada por la estética clásica como elemento pleno de belleza y armonía), por un lado; y por otro, representa la imperfección de la existencia humana. La visión de una mutilación constante en la vida del hombre. De igual modo, el arte clásico se configura como una totalidad escindida, imperfecta:

Venus de Milo, cuyo cercenado, increado (v. 13) brazo revuélvese ...

Venus de Milo símbolo de la estética tradicional expone las deficiencias que parecen persistir, tal como lo sugiere el neologismo "todaviiza". Ante esta insuficiencia del discurso poético se crea la escritura nueva desde un ámbito vivencial. Como lo refieren las imágenes de los versos:

a través de verdeantes guijarros gagos, (v.15)

ortivos nautilos, aunes que gatean

recién, vísperas inmortales.

(Énfasis mío) 
Se establece como experiencia de vida dinámica (verdeantes: el color verde adquiere el sentido de vida en el poemario), no obstante, la poética clásica considera que la nueva poesía es incapaz de expresión plena (gagos). Asociamos este concepto con el lenguaje de Trilce, un lenguaje sumamente obscuro, difícil que representa la visión negativa que el hombre tiene de su destino. Aparte de ello, la organización de los vocablos y las estructuras gramaticales complejas quebrantan la armonía entre la intuición poética y las formas del lenguaje lo que hace bastante difícil la lectura y comprensión del poemario.

ortivos nautivos, aunes que gatean (v.16)

Trilce revela un universo inédito que se crea a partir de la elaboración singular de la escritura poética. El lenguaje anota la emoción del hombre y del artista. Esta es la diferencia con la poesía vanguardista de la época que hizo del lenguaje una experimentación formal alejada de la auténtica emoción humana. Conviene, sin embargo, advertir que estos caracteres no lo apartan del conocimiento ni de las coincidencias con el vanguardismo literario.

Vallejo declaró siempre su continuo rechazo a las corrientes literarias. Así lo dice en su artículo Poesía Nueva:

Poesía nueva ha dado en llamarse a los versos cuyo léxico está formado de las palabras "cinema, motor, caballos de fuerza, avión, radio, jazz-band, telegrafía sin hilos", y en general, de todas las voces de las ciencias de industrias contemporáneas, no importa que el léxico corresponde o no a una sensibilidad auténticamente nueva. Lo importante son las palabras.

Pero no hay que olvidar que esto no es poesía nueva ni antigua, ni nada.

[...] La poesía nueva a base de sensibilidad nueva es, contraria, simple y humana [...]. (Verani 1995, p. 190)

Sin embargo, se señala que:

¿Puede negarse, no obstante, que los procedimientos de escritura que Vallejo reprueba son recursos usuales de su poesía? Anomalías gráficas, blancos espaciales, imágenes visuales, lenguaje desarticulado, desviaciones gramaticales, ausencia de puntuación, alteración de la lógica y asociaciones desconcertantes son rasgos distintivos que vinculan a Trilce con la poesía que Vallejo niega. (Id. p. 28)

Estas características son coincidencias con el movimiento literario de la época, pero no determinan que el poemario responda a las inquietudes estéticas de la vanguardia. La singularidad de Trilce, obedece a una voluntad de quebrantar las estructuras establecidas de la escritura y construir un universo poético que exprese de modo exacto la realidad y la vida espiritual del hombre. 
Retomenos la lectura de la tercera estrofa de Tr. XXXVI, meollo de la composición:

Rehusad la simetría a buen seguro. (V.22)

Aquí el poeta exhorta a los artistas a apartarse de la estética tradicional y emprender una nueva aventura poética. Esta ha de concebirse a partir de la noción de desarmonía como elementos de libertad artística. Esta nueva poética deberá estar en función de la percepción de la realidad y del ser. Así, expone su modo de ver la existencia

humana como una trama de pugnas (puntas, toriondas, justas), imperfecciones e imposibles (salto por el ojo de una aguja). Como se sugiere en los versos

de puntas que se disputan (v.24)

en la más torionda de las justas

el salto por el ojo de la aguja.

Hemos observado en las tres composiciones (I, LXXVII, XXXVI) aspectos de la escritura que determinan a Trilce como un libro de creación particular. En Tr. I desde la metáfora de la defecación se enuncia el alumbramiento de la nueva poética. El tratamiento del tema es notable, pues se poetiza la descripción del acto de la defecación para exponer su arte nuevo, y no solo eso, cuestiona el medio en que el artista tiene que desarrollar la creación lírica. Vallejo continúa reflexionando sobre su propia palabra y la inspiración lírica como lo refiere en el poema LXXVII. Comprender la complejidad lexical, la obscuridad de su poesía exige entender la visión que Vallejo tiene de la realidad, del ser y del mundo. El poeta descubre un mundo de contrarios inconciliables, fragmentario siempre imperfecto tan igual que la estética tradicional. Por ello, exhorta a distanciarse de la poética establecida y crear la poesía desde la emoción humana. "La poesía nueva a base de sensibilidad nueva es, al contrario, simple y humana [...]" Vallejo (ctd en Verani 1995, p. 191).

Es necesario recalcar que, el lírico santiaguino quebranta todas las tradiciones literarias y se distancia de toda pretensión de influencia vanguardista. $\mathrm{El}$ poemario permanece al margen de las vanguardias. Como lo afirma en sus años parisinos, en el libro, Contra el secreto profesional, en el que dice: "Ninguna de las formas literarias me han servido. Ninguno de los accidentes del verbo. Ninguna de las partes de la oración. Ninguno de los signos de puntuación". (Vallejo 1973, p. 53)

Aparte de ello, resulta oportuno señalar las conclusiones que hacen Martos y Villanueva sobre la relación entre Vallejo y las vanguardias: 
No existe pues subordinación a la poesía europea aunque casi todos los "ismos" hayan nacido ahí; Vallejo no es un colono literario ni está subordinado a un medio del que es resultado, sino que es interpretador de su circunstancia. [...] Mientras los vanguardistas juegan con el lenguaje, hacen los arabescos en el papel en blanco, Vallejo pelea con las palabras, las hace rechinar, les hace decir lo que ellas no esperan. (1989, p. 21)

Sobre la base de lo anterior, Trilce, es un libro impar. No corresponde a las inquietudes estéticas de la vanguardia de la época. A pesar de los aspectos que parecen asociarla con este movimiento como la ruptura con la retórica tradicional, el año de la publicación, 1922, fecha clave para la vanguardia europea e hispanoamericana y; ciertos procedimientos de escritura de la poesía vanguardista, por ejemplo, las anomalías gráficas, el uso de números, los espacios en blanco, ausencia de puntuación, alteraciones lógicas, asociaciones desconcertantes.

En conclusión, no se puede negar que Vallejo tuvo conocimiento de los movimientos de vanguardia europeos y latinoamericanos (Manifiestos: Le Figaro, 1909; Panopla lírica, 1916 y otras revistas de vanguardia). Sin embargo, se mantiene al margen de toda escuela vanguardista. No obstante, en Trilce, lo admirable no es la similitud de su poesía con este movimiento estético sino las diferencias. Lo que cambia, en la poesía trílcica, es la transformación de la escritura. Este proceso de adecuación entre la palabra y el sentido que se le otorga al mundo. La escritura trílcica es la ruptura definitiva con el mundo tradicional, con el lenguaje que nombra para reemplazarlo con el lenguaje que represente de manera íntegra la realidad y la vida afectiva del poeta.

\section{Referencias}

Burga, Manuel y Alberto Flores Galindo. (1980). Apogeo y crisis de la República Aristocrática (Oligarquía, Aprismo y Comunismo en el Perú 1895 - 1932). Lima: Ediciones RICHAY PERÚ.

Bürger, Peter. (2000). Teoría de la vanguardia. $3^{\text {era }}$ ed., Barcelona: Península.

Espejo Asturrizaga, Juan. (1960). César Vallejo - Itinerario del hombre, (1892 - 1923). Lima: Seglusa Editores.

Delgado, Washington. (1980). Historia de la Literatura Republicana. La Paz: Ediciones Rumi.

Ferrari, Américo. (1997). El universo poético de César Vallejo. Ensayo. Lima: El Heraldo.

Martos, Marco y Elsa Villanueva. (1989). Las palabras de Trilce. Lima: Seglusa Impresores S.A.,

Neale-Silva, Eduardo. (1975). César Vallejo en su fase trílcica. Madrid: escelicer. 
Schwartz, Jorge. (2002). Las vanguardias latinoamericanas: textos programáticos y críticos. Trad. de Estela Dos Santos-México: Fondo de Cultura Económico.

Verani, Hugo H. (1995). Las vanguardias literarias en Hispanoamérica (manifiestos, proclamas y otros escritos). $2^{\mathrm{a}}$ ed. México: Fondo de Cultura Económica.

Vallejo, César. (1973). Contra el secreto profesional. Lima: Mosca Azul Editores.

-. Obra poética completa. (1982). Madrid: Edición de Américo Ferrari.

—. Trilce. (1998). Julio Ortega (ed.). Madrid: Ediciones Cátedra, S. A.

- Desde Europa, Crónicas y artículos (1923 - 1938). (1987). Jorge Puccinelli (comp.). Lima: Ediciones Fuente de Cultura Peruana. 
